International Journal of Engineering \& Technology, $7(1.1)(2018) 78-83$
International Journal of Engineering \& Technology
SPC
Website: $w w w . s c i e n c e p u b c o . c o m / i n d e x . p h p / I J E T$
Research paper

\title{
Study of the mechanical performance and analysis of hybrid natural snake grass-jute-glass fiber strengthened polyester composite
}

\author{
C. Thiruvasagam ${ }^{1 *}$, S. Prabagaran ${ }^{2}$, P. Suresh ${ }^{3}$ \\ ${ }^{1}$ Research Scholar, Dept. of Mechanical Engineering, Karpagam Academy of Higher Education, Coimbatore, Tamilnadu, India \\ ${ }^{2}$ Professor, Dept. of Mechanical Engineering, Karpagam Academy of Higher Education, Coimbatore, Tamilnadu, India \\ ${ }^{3}$ Professor, Dept. of Mechanical Engineering, Muthayammal Engineering College, Rasipuram, Tamilnadu, India \\ *Corresponding author E-mail: thiruvasagamc33@outlook.com
}

\begin{abstract}
The research paper involves fiber composites form a special category materials that are contributing to present swaping of manufactured hybrid which finds traditional and non traditional applications. The study explains which are accentuates and optimizing for the recently recognized snake grass standard materials. In this article, the prospecting performance characterization of SG fiber is selected and contrasted as per the ASTM standard. This study additionally manages the examination apply different phenomena of this stages in Jute and snake as fortifications utilized index ended a try. Experiments have been conducted on normal Filaments, snake grass, Glass Fiber and Jute to analyse their Mechanical properties. The common strands are orchestrated in the flat and vertical heading as transferred quality on all sides. Microstructural analysis of these hybrid composite is observed using Scanning Electron Microscope that reveals bonding and Filament breaksge, Voids and Fiber decover which are further investigated.
\end{abstract}

Keywords: Snake Grass, Glass Fiber, Mechanical Properties, Reinforcement.

\section{Introduction}

The matrix of asset composition of minimum two artificially unmistakable constituents, and highlights of measuring the scale and particular line isolating them. At most of the intermittent stage in this manner were encompassed in a persistent stage to shape a composite. Basic fiber composites broadly utilized rather than manufactured filaments with of their focal points like biodegradability, less mass and meager effort and atmost behaviors of the when compared with common Fiber matrix. Since they cost more, they are utilized in Aerospace and Military applications. The best creator has already examined composites with normal strands support with polymer matrix or grids [1-5] GF is being explained Glass Fiber as a study if reinforced polymers [GFRP] is an instance of polymer built on some plastic networks highly reinforced by combinations of filaments -glass. A fiber glass are the lightest duty, solid and powerful material assigns as a part of different ventures with consumable incredible properties. Regular strands were extracted from plants like Plantain fiber, Ercanutfiber, and sugarcane. These plants are available in equatorial with central regions and different, consequently process support in meager effort of composites [13]. The re-informant stage should be sideways or stringy [particular] in nature and fabric filaments and other living species, The normal strands. Normal fiber, metal matrix composites consolidate plant determined filaments in plastic fabric folio materials. The Normal fiber parts might be wood, sisal, hemp, coconut, cotton, kenaf, flax, jute, abaca, banana leaf stands, bamboo and classified the stringy materials. Benefits of most normal fibers metal matrix of compositions incorporate medium weight and low -vitality generation and ecological and agreeable to present some examples. The utilization of common filaments diminishes weight by $10 \%$ have down -up vitality is required for creation by $80 \%$, however, the cost-effectiveness is $5 \%$ lower is compared with experimental identified fiber glass-fortified segment[6]. Many researchers have proved that the characteristics of regular composites can be improved by additional treatment. Franco-Herrera and Valdez-Gonzalez [7] demonstrated that ductile bending and shear characterization of those short fibre can be achieved by Saline and pre impregnation processes. Alwar [8] demonstrated that Mechanical properties can be improved by Alkali $(\mathrm{NaOH}$ solution) treatment of Date palm fiber and disintegration of its characterisation by Acid $(\mathrm{HCl})$ treatment. The hybrid fiber stretched material band was deceit by Cicala et al.84 with a reduction of cost and $20.2 \%$ and a lightweight reduction of $23.5 \%$ when hemp has been applied pipe architectural [9]. Venkateshwara [10] The build of sisal as a maximum of $50 \%$ increase the shear strength with responding the composite behavior and impact strength consist $4 \%, 16 \%, 35 \%$ respectively. SG filaments werespecificallyutilized the water retting process and the tractable properties of these characterization stands were parametricanalyzed with measured by the benchmarks. The SG composites were appropriate structure haphazardly situated fiber strengthened polyester matrix by the pressure forming process and behavior of materials was studied for different fiber parameters should take fiber volume divisions. In this research reviewed one normal fiber to take SG composite materials distinct from actual accessible plants. Snake grass strands were extracted from its plants [Sansevieria ehrenbergii] by traditional process and this plant was abundantly grown in South India. This research work has additionally reached out to make the strengthened composite utilizing the polyester to study hybrid performances. Vijaya 
Ramnath [14] narrated in his work that \% of elongation of Hybrid Composite was more than that of Single Fiber Composite. While the fatigue response of under cyclic tensile load with respect to bamboo/glass fiber polypropylene composite as derived. After the analysis of thermal system against should be properties were moderately reduced [15]. This article describes the procedures on Manufacturing and Characterisation of Snake Grass, Jute and Glass Fiber found to have improvements in Mechanical and Flexural properties.

\section{Methodology}

\subsection{Fabrication of snake grass fiber}

Length of the Snake Grass plants were grown in the field between 0.3 to 1.2 meters. Snake Grass were cut from the plant and sticking sands were cleaned thoroughly by water. External green layers had been removed. The SG was soaked in water for about continuous $96 \mathrm{hrs}$. This biodegradable procedure supported in the removal of filaments from the plant without any damage. Samples of SG being taken in $10 \mathrm{~mm}, 30 \mathrm{~mm}, 60 \mathrm{~mm}$ and $120 \mathrm{~mm}$ lengths.

\subsection{Fabrication of jute fiber}

Jute is a rarer than best tolerable regular filaments. It is primarily formed plant materials like cellulose and it can revolve causes meshing or solid strings. Jute took almost 12 weeks to grow to a length of about 4 meters and for the establishment to isolate the metal fiber starts stem of green holes. The real prospects retreating are mechanical retting, concoction retting steam setups, and water absorption system to take places and dried in outdoors were utilizing mechanical methods.

\subsection{Glass fiber fortified polymer}

The Hybrid GF explains Glass fiber is a most effective material is considered great degree fine strands. This medium capacity and lightweight drove and amazingly solid and strong shaped were strands of silica glass was expelled into numerous filaments with little measurements. The mass quality and lightweight characterization analyze it. The mono fibers were presently packaged together in most numbers to have wandered. The woven while a wind machine to create woven wandering. When all is said and done, This most appropriate as a fortifying specialist for composites to shape an exceptionally solid and medium fiber reinforced polymer [FRP] composite materials.

\subsection{Polyester resin}

Economically, while accessible isophthalic implicit polynomial materials, tar is utilized in these examinations. Quickening agent and the impulse of curing the sap.Thermostat isophthalic polyester resin is mono oh the efficient resins while to take up and delivered classification resins to selected and allows water retaining capacity and brilliant holding inclination and additional mechanical properties.

\subsection{Planning of the composite Sample}

Consecutive 96 hrs, the separated SG strands are taken out simulated an $\mathrm{H} 20$, Then the $\mathrm{H} 20$ content present within the matrix expelled by keeping a regular formation air simulated at eight hours. At that point, the filaments are kept in the hot air broiler for 60 min at 160 degree centigrade [8]. The preserved Filaments then slashed into the classification of parameters as said before, to classify the setting composites. The pressure is adjusted to setup the combination examples with classified volume portions (VF) like $10 \%, 15 \%, 20 \%, 25 \%$ and $30 \%$ individually. The current of impetus and existing of quickening agent are appropriate to antidote the isophthalic polyester resin. Steel passes were intended to arrangements of the composition examples. Fiber introduction and consistency in this matrix of composites are kept up a moving procedure utilizing steel rollers to accomplish at the expect isophthalic material property and all the air pockets are expelled by the constant moving procedure. As the season of curing, the shut shape is continued with the $\mathrm{H}_{2} \mathrm{O}$ powered press and a compressive weight is connected for $8 \mathrm{~h}$ at barometrical temperature. At long last the hybrid filaments are fortified with the polyester resin at long last the filaments are fortified with the polyester resin inside the farm depression of measurements $230 \mathrm{~mm} \times 200 \mathrm{~mm} \times 4 \mathrm{~mm}$ to setting the required composite plate. After cementing development, the composite plate is then upright and preserved for one hour in the boiler.

\section{Experimental procedure}

\subsection{Mechanical testing of composite}

The tractable conduct of semitype composites was measured utilizing the widely measurement machine at a cross-head 22 stroke of $1000 \mathrm{~mm}$ and permission between columns $=650 \mathrm{~mm}$. Range of testing $=$ OKN . Power supply $=1 \mathrm{PH}, 230 \mathrm{~V}$ A.C and $50 \mathrm{~Hz}$. Conferring to the ASTM D-3039 Standard. The examples were cut from the manufactured composite in the surmised breadth, thickness and width of $250 \mathrm{~mm}, 25 \mathrm{~mm}$ and $3 \mathrm{~mm}$ separately. Three indistinguishable arrangements of examples were trying to acquire the usual elasticity of that esteem every synthesis for a better outcome. Three singleshots of example are read in interpretation of elements applied to be specific, snake grass [SG]-glass fiber [GF] strengthened composite, jute [J] -glass fiber encouraged composite and snake-jute-glass fiber fortified composite. They are appearing in the fig. 1.

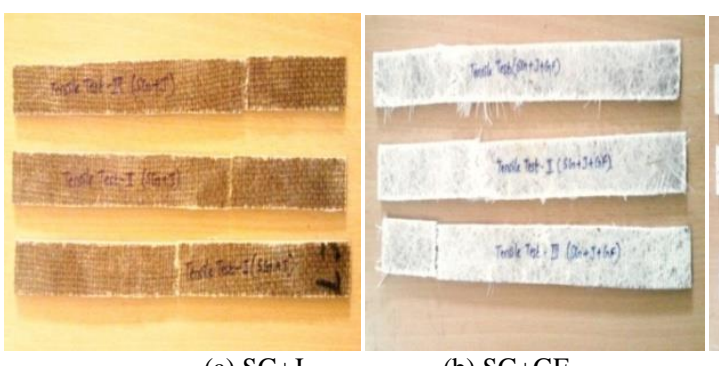

(a) $\mathrm{SG}+\mathrm{J}$ (b) $\mathrm{SG}+\mathrm{GF}$

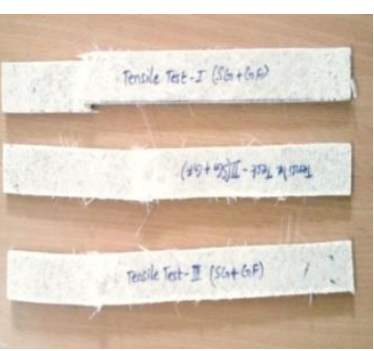

(c) $\mathrm{SG}+\mathrm{GF}+\mathrm{J}$

Figure 1: Tensile tested specimens

\subsection{Flexural experimentations}

Samples as per ASTM D790 had been made and ensured for its specifications. Tests had been conducted with different composites of SG, Jute Fiber, GF. Experimental procedure was that clamping the samples in the Machine jaws and force was applied on to it gradually until fracture occurred at the ambient condition of $23+/-2$ degree centigrade temperature and at $50 \%$ of humidity value. The readings of displacement and Flexural strength Subsequently the flexural strength and modulus had been 
calculated and tabulated in Table 2 . The models as shown in the figure 2 as maximum fiber as consumed stress at failure on the tension side of a flexural measurement model considers the flexural strength of the material. The Samples were cut from the fabricated composites in the approximated parameter of length, width and thickness of $125 \mathrm{~mm}, 13 \mathrm{~mm}$ and $3 \mathrm{~mm}$ correspondingly. Three identical sets of samplings were tested to consume the average bend tested values each composition for better results. It is shown in the figure 2 .

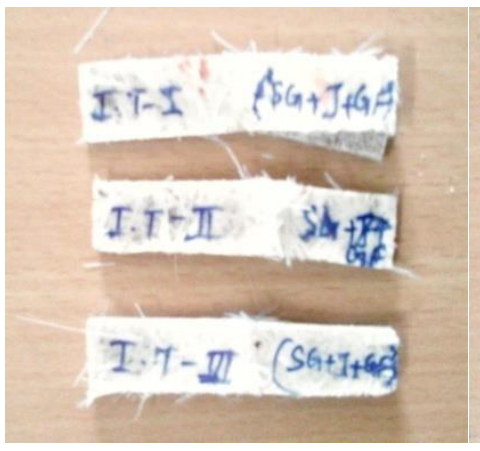

(a) $\mathrm{SG}+\mathrm{J}+\mathrm{GF}$

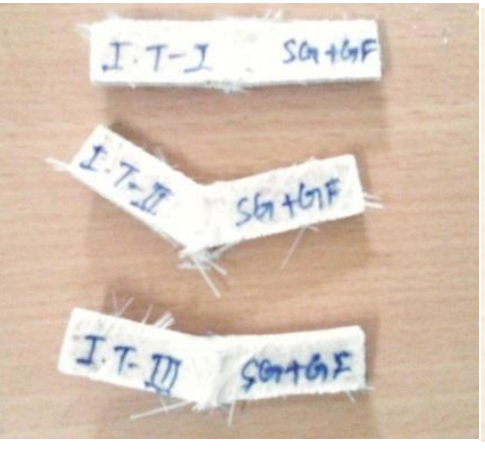

(b) $\mathrm{SG}+\mathrm{GF}$

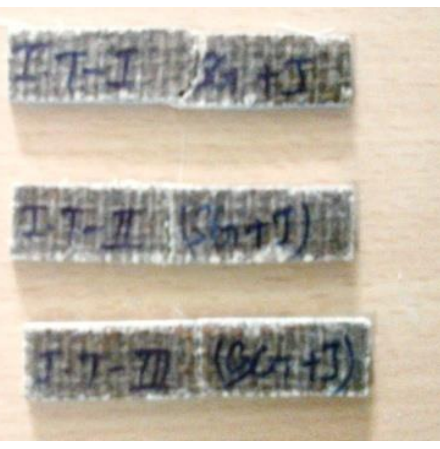

(c) $\mathrm{SG}+\mathrm{J}$

Figure 2: Impact tested specimen

\section{Results and discussion}

\subsection{Elastic characteristics}

The three diverse composite samples of SG-Jute fiber strengthened composite, snake grass-Glass fiber encouraged matrix and SG -jute-Glass fiber strengthened metal matrix are tried in the all inclusive measurement machines to locate the tractable properties. The different Mechanical characterization of the created metal matrix is compressed in the table 1 for better examination.

It is unmistakably observed as rigidity of the SG and Glass fiber, metal matrix composite was high. In spite of high rigidity, the pliable modulus of the metal was not as much as that of SG and Glass fiber. Then the other two sorts of composite was considered. The development of snake filaments indicates nearly low elasticity than alternate composites measured. A snake-jute-GF cross breed composite perform superior to the snake strands. A definitive elasticity (UTS) of the SG- GF composite, SG-Jute composite and snake grass-jute-GFRP composite was in the scope of 76.24 Mpa, 26.14Mpa and 47.95Mpa respectively. The consequences showed that the SG- GFRP composite outflanked alternate kinds of composite tried. Beginning to value assign, it should be stated that the SG- GF Metals were performing very much compared with the other kind of elements utilized.

A definitive elasticity (UTS) SG-GF composite, SG-Jute composite and SG-jute-GFRP composite is in the scope of 76.24 Mpa, 26.14Mpa and $47.95 \mathrm{Mpa}$ separately. The beginning as shown that the SG-GFRP composite outflanked alternate sorts of composite tried. From the outcomes, it should be stated that the SG-GF fiber composites are performing very much compared with the other kind of elements utilized.

This demonstrated when all is said and done the rate extension of Mono fiber composite was unused as much as that of the Semi category composite which implied that the blend composite withstood more strain than that of Mono fiber composite before disappointments. Similarly jute fiber support was expanding better than the other common fiber. For this to happen, more adjustable formulations was arrived that was better than the computation of SG-GF composites. From the malleable tests, it was made to conclude that fiber composites GF works better for different composites of materials.

Table 1: Result of Tensile Test of Different Composites

\begin{tabular}{|l|l|l|l|l|}
\hline Composite Composition & Applied load in KN & Highest displacement in mm & Percentage Elongation & Tensile strength in MPa \\
\hline SG + GF & 5718.49 & 75 & 3.2 & 76.243 \\
\hline SG + JUTE & 1960.81 & 75 & 1.46 & 26.144 \\
\hline SG + JUTE + GF & 3596.56 & 75 & 2.4 & 47.951 \\
\hline
\end{tabular}

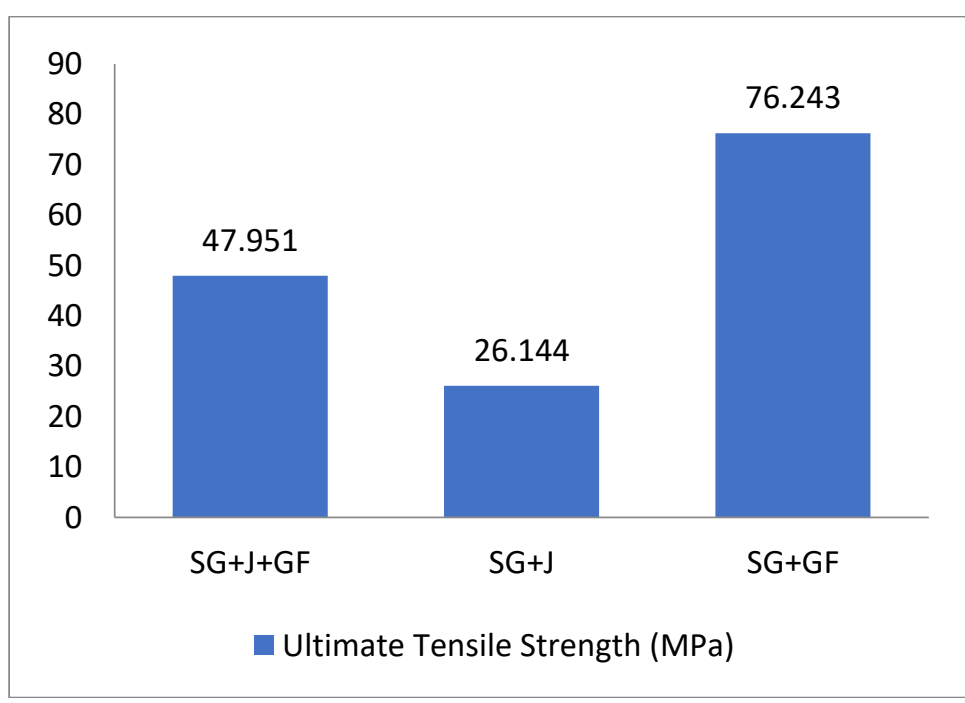

Figure 3: Comparison of different composition of tensile strength 


\subsection{Flexural properties}

The curve quality protections showed up by various composites are showing up in Table 2.

Wind composite is most bewildering flexural protection in light of the closeness of reliably passed on abaca strands and its high robustness besides; the bond between the snake grass fiber and the epoxy framework was better than that of other two composites. The flexural strength of the composite was found from the immediate piece of the twist by choosing the pile and its relating movement which showed wind grass that had the most vital flexural strength when stood out from other two composites. The flexural breaking load of alpaca was 1.26 conditions that of jute and conditions that of snake grass and jute mutt composite. The most outrageous dislodging was vaguely higher for the alpaca fiber, which was 1.07 conditions that of jute and 1.05 that of alpaca and jute creamer breed composite. After the most extraordinary flexural stake point, the graph diminished and showed aimless directed since the strands tend to pull out from the campsite at the farthest point. This prompted to subjective augment and reducing of twist in graph before it finally broke. The nerves started in the composite are essentially same for all as shown in table 2.

Table 2: Outcome of Flexural Test for Different Composition of Composite

\begin{tabular}{|l|l|l|l|l|}
\hline Composition of Composite & Flexural applied load in KN & Highest displacement in mm & Flexural strength in MPa & Flexural Modulus in GPA \\
\hline SG + GF & 180.72 & 39 & 145.44 & 12334.405 \\
\hline SG + JUTE & 97.12 & 39 & 82.26 & 6853.496 \\
\hline SG + JUTE + GF & 108.74 & 39 & 114.92 & 6786.888 \\
\hline
\end{tabular}

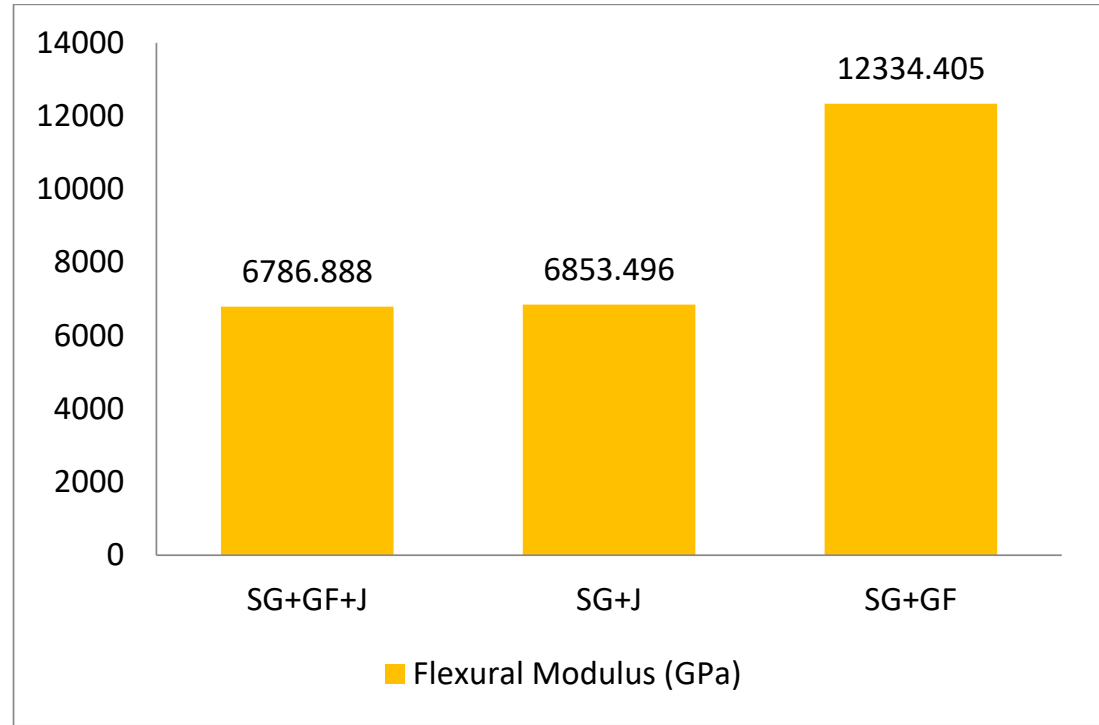

Figure 4: Comparison of different composition of flexural modulus

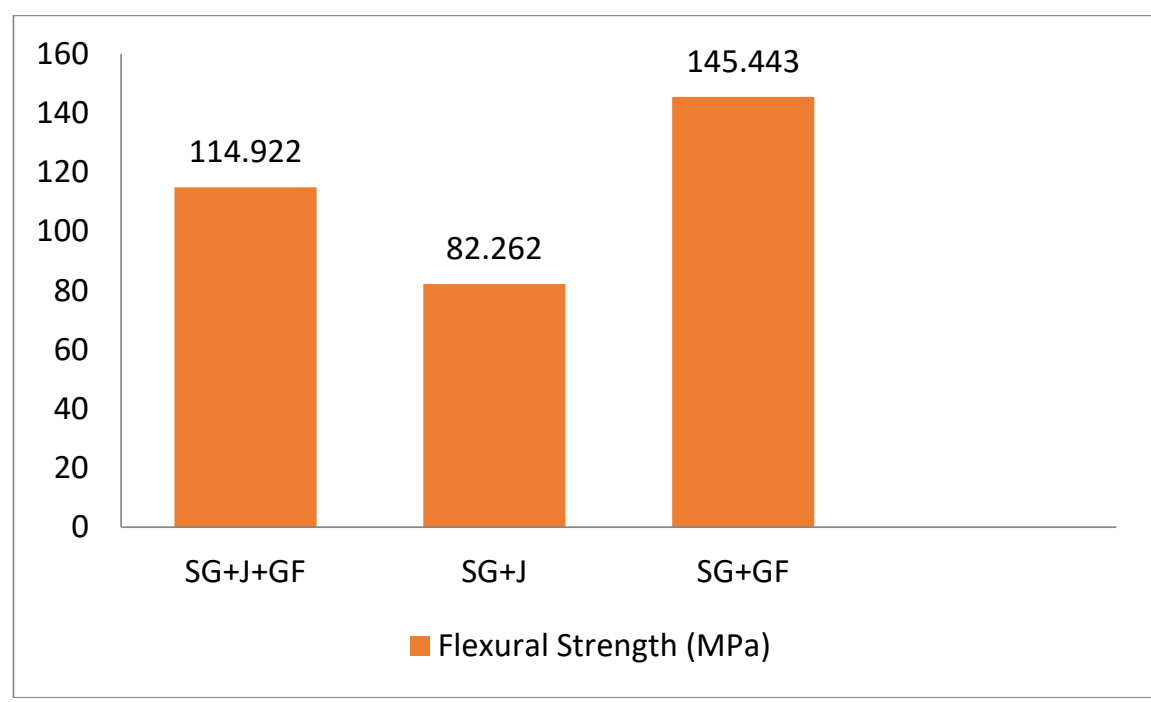

Figure 5: Comparison of different composition of flexural strength

\subsection{Impact test}

The impact test wais encouraged for separating the impact furthest reaches of three remarkable composites as defined it. The most of significance was found using a charpy impact test machine. The imperativeness ate up by every circumstance when it was influenced by a shocking blow which was captured in table 4 . Mallick and broutman [11] had proved that stacking get-together of the strands crucial than blend in picking influence quality. It could be seen that the alpaca had high impact quality when risen up out of exchange composites. The clarification for such high bore was a quick delayed consequence of the closeness of single sort fiber in the structure in substituting presentation. In that way when the break spreads, it experiences the system and the strands of the composite. When it accomplishes the aggregate of the fiber in a particular course, it moves to the running with a layer of strands show in a substitute heading. This alteration in layers holds, the more significant, importance of making a more surface scope of split than a composite which is arranged in only a solitary course. Snake-GF composite shows the most fundamental impact 
quality in light of the face that the alpaca fibers have consummate quality over the jute strands. Jute fiber has a bye and large captivating nature of $2.75 \mathrm{~J}$ which is closer to the snake strands. The clarification for such high bore is a quick delayed consequence of the closeness of single sort fiber in the structure in substituting presentation. In this way when the break spreads, it experiences the system and the strands of the composite. When it accomplishes the aggregate of the fiber in a particular course, it moves to the running with a layer of strands show in a substitute heading. This alteration in layers holds, the more significant, importance of making a more surface scope of split than a composite which is arranged in only a solitary course. Snake-GF composite shows the most fundamental impact quality in light of the face that the alpaca fibers have consummate quality over the jute strands. Jute fiber has a bye and large captivating nature of $2.75 \mathrm{~J}$ which is closer to the snake strands.

Table 3: Outcome of Impact Test for Various Composites

\begin{tabular}{|l|l|}
\hline Composition of Composite & Impact Strength in joules \\
\hline SG + GF & 3.25 \\
\hline SG + JUTE & 0.50 \\
\hline SG + JUTE + GF & 3.6 \\
\hline
\end{tabular}

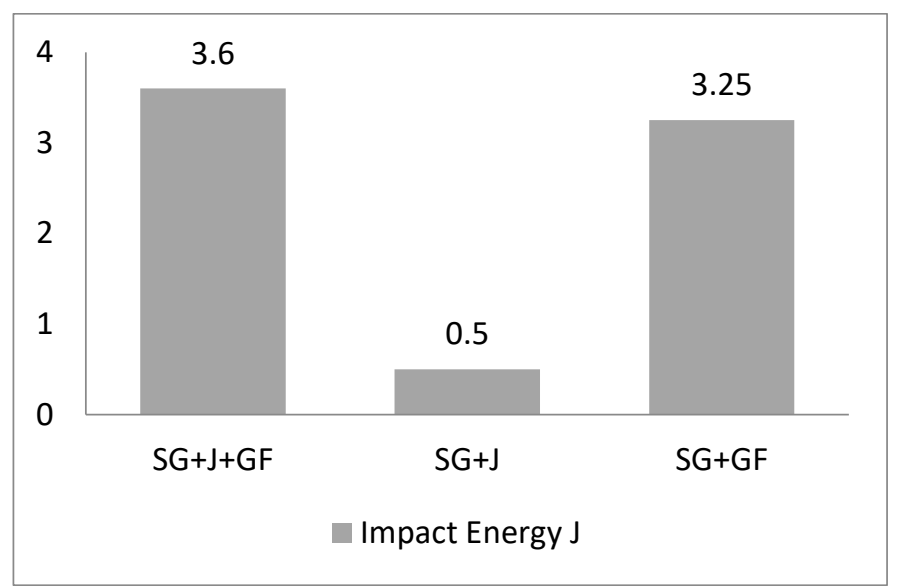

Figure 4: Comparison of different composition of impact strength

\subsection{Electron microscopy (SEM) examination}

Morphological examination was conducted in a Scanned Electron Microscope. Samples of each test had been dried and coated with a gold layer of 15 to 20 microns thickness. Thus the cases were investigated by viewing at electron magnifying instrument. Interfacial bonding between the Snake Grass and Glass Fibers was observed in SCM as shown in figure 5a. Each sample was secured with leading materials before observing the surface in Samples of Jute + Glass Fiber + Snake Grass hybrid composite showed the filament breakage, Inadequate dissemination of fiber and grid in composite materials which are shown in Figure 5c.

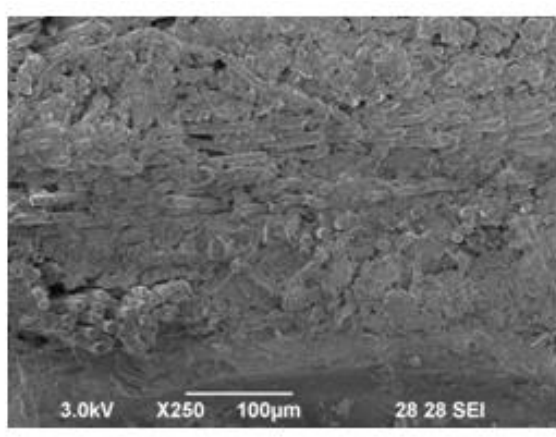

Figure b. SG $+\pi$ TTE

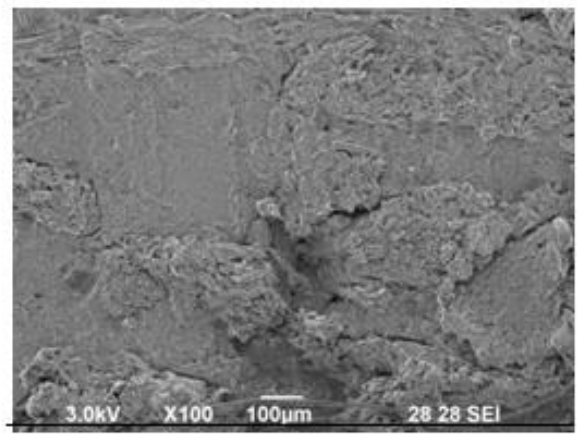

Figure c. Snake grasa + Jute + GF

Figure 5: Electron microscopy (SEM) examination 


\section{Conclusion}

The snake grass, Glass fiber an jute composites were made by fabrication. These samples were characterized for their Mechanical properties viz. Tensile test, Flexural test, Impact test by Charpy method. Test results had been analysed and inferences were drawn as detailed below.

1. This investigation proved that the SG and GF composite materials resulted improved Tensile strength of 76.24MPa maximum.

2. The Snake grass and Glass Fiber hybrid composite specimen resulted enhanced Flexural strength upto 18.72 $\mathrm{KN}$ with $39 \mathrm{~mm}$ evacuation.

3. SG/Jute/GF hybrid composite resulted an improved Impact strength of 3.6 Joules.

4. Microstructural analysis by SEM revealed that uniform breakage of filaments were seen in Jute and Fiber Glass hybrid composite.

\section{References}

[1] El-Tayeb NSM, "A study on the potential of sugar cane fibers/polyester composite for tribological applications", Wear, Vol.265, No.1-2, (2008), pp.223-235.

[2] Iricula M, Malhotra SK, Joseph K \& Thomas S, "Dynamic mechanical analysis of randomly oriented intimately mixed short banana/sisal hybrid fiber reinforced polyester composites", Compos Sci Technol, Vol.65, No.7-8, (2005), pp.1077-1087.

[3] Kaddami H, Dufresne A, Khelifi B, Bendahou A, Taourirte M, Raihane M, Issartel N, Sautereau H, Gerard JF \& Sami N, "Short palm tree fibers-Thermoset matrices composites", Composites Part A:Applied Science and Manufacturing, Vol.37, No.9, (2006) pp.1413-1422.

[4] Surendar, A., Arun, M., Basha, A.M."Micro sequence identification of bioinformatics data using pattern mining techniques in FPGA hardware implementation",(2016) Asian Journal of Information Technology, 15 (1), pp. 76-81.

[5] Yousif $\mathrm{BF} \& \mathrm{Ku} \mathrm{H}$, "The suitability of using coir fiber/polymer composite for the design of liquid storage tanks", Mater Des Vol.36, (2012), pp.847-853.

[6] Prabu, G., Surendar, A."Virus detection by using a pattern matching algorithm for network security",(2015) International Journal of Applied Engineering Research, 10 (10), pp. 9565-9569.

[7] Herrera-Franco PJ \& Valadez-Gonzalez A, "A study of mechanical properties of short natural fiber reinforced composites", Compos B Vol.36, (2005), pp.597-608.

[8] Alawar A, Hamed AM \& Al-Kaabi K, "Characterization of treated date palm tree fiber as composite reinforcement", Compos: Part B Eng, Vol.40, No.7, (2009), pp.601-606.

[9] Surendar, A., Arun, M.'FPGA based multi-level architecture for next generation DNA sequencing",(2016) Biomedical Research (India), 2016, pp. S75-S79.

[10] Venkateshwaran N, ElayaPerumal A, Alavudeen A \& Thiruchitrambalam M, "Mechanical and water absorption behavior of banana/sisal reinforced hybrid composites", Materials \& Design, Vol.32, No.7, (2011), pp.4017-4021.

[11] Mallick PK \& Broutman LJ, "Static and impact properties of laminated hybrid composites", J Test Eval, Vol.5, (1977), 190-200.

[12] Sathishkumar TP, Navaneethakrishnan P \& Shankar S, "Tensile and flexural properties of snake grass natural fiber reinforced isophthallic polyester composites", Composites Science and Technology, Vol.72, (2012), pp.1183-1190.

[13] Sreenivasan VS, Ravindran D, Manikandan V \& Narayanasamy R, "Mechanical properties of randomly oriented short Sansevieria cylindrical fiber/polyester composites", Materials and Design, Vol.32, (2011), pp.2444-2455.

[14] Vijaya Ramnath B, Junaid Kokan S, Niranjan Raja R, Sathyanarayanan R, Elanchezhian C, Rajendra Prasad A \& Manickavasagam VM, "Evaluation of mechanical properties of alpaca-jute-glass fiber reinforced epoxy composite", Materials and Design, Vol.51, (2013), pp.357-366.

[15] Thwe MM \& Liao K, "Durability of bamboo-glass fiber reinforced polymer matrix hybrid composites", Compos Sci Technol, Vol.63, (2003), 375-387.
[16] Noorunnisa Khanam P, Mohan Reddy M, Raghu K, John K \& Venkata Naidu S, "Tensile, flexure and compressive properties of sisal-silk hybrid composites", J ReinfPlast Comp, Vol.26, (2007), pp.1065-1070.

[17] Pavithran C, Mukherjee PC \& Brahma Kumar M, "Impact properties of sisal-glass hybrid laminates", J Mater Sci, Vol.26, (1991), pp.452-459.

[18] Murali Mohan Rao K, Mohana Rao K \& Ratna Prasad AV, "Fabrication and testing of natural fiber composites: Vakka, sisal, bamboo and banana", Materials and Design, Vo.31, (2010), pp.508-513.

[19] Velmurugan $\mathrm{R}$ \& Manikandan V, "Mechanical properties of Palmyra/glass fiber hybrid composites", Composites Part A, Vol.38, No.10, (2007), pp.2216-2226.

[20] Boopalan M, Niranjanaa M \& Umapathy MJ, "Study on the mechanical properties and thermal properties of jute and banana fiber reinforced epoxy hybrid composites", Composites: Part B, Vol.51, (2013), pp.54-57. 